\title{
LAS GALÁPAGOS EN EL IMAGINARIO FUNDACIONAL DEL ESTADO- NACIÓN LATINOAMERICANO: EL PIRATA DEL GUAYAS DE MANUEL BILBAO
}

\author{
POR \\ Esteban Mayorga \\ Niagara University
}

Bilbao nació en Chile en 1827 y murió en Argentina casi setenta años más tarde. Vivió en este último país por un tiempo considerable así como en el Perú y en el Ecuador, exiliado, por seis meses. Este autor representa perfectamente la figura del intelectual u hombre público del siglo XIX latinoamericano: fue abogado, periodista, diplomático, traductor, editor e historiador. Aunque tal vez sus obras más conocidas sean historiográficas ${ }^{1}$ su relativa fama surge por haber escrito, en 1852, El inquisidor mayor, la primera novela chilena. ${ }^{2}$ Bilbao también fundó la literatura de ficción de las islas Galápagos en español con la publicación, en Guayaquil y en Lima en 1855, de la novela El pirata del Guayas. ${ }^{3}$ Este texto se volvió a editar y publicar en Valparaíso (1865), Buenos Aires (1871) y Guayaquil (1904) (Quiroz 9-10).

La novela sobre el pirata y aquella sobre el inquisidor, tanto en Chile como en Ecuador, cobran una importancia inusual leídas bajo la lente de la "ficción fundacional", cuya tesitura principal es "mostrar lo inextricable de la política y la ficción en la historia de la creación del estado-nación" (Sommer 5-6). Si bien el género fundacional ecuatoriano no es la novela sino la crónica periodística como muestra convincentemente Burgos (67-75), El pirata del Guayas antecede en casi una década a La emancipada (1863) de Miguel Riofrío, texto que este crítico posiciona como pionero en detrimento del que postula Sommer, Cumandá o un drama entre salvajes, de Juan León Mera, que se publicó en $1879^{4}(237-40)$. La discusión con respecto a la formación de la nación y

1 Historia del general Salaverry (1853), Historia de Rosas (1868) y Compendio de la geografía del Perú (1856).

2 Sobre sus obras literarias dice Quiroz: "Es posible distinguir una breve etapa novelística en la producción intelectual de nuestro autor, puesto que la totalidad de sus obras de ficción -en rigor solo tres- fueron compuestas en el lapso de tres años (1852-1855), aunque fueron posteriormente revisadas y corregidas" (10).

3 Título que tal vez inspirara el relato de Juan Montalvo "Los piratas del Guayas" (1876-8).

4 Como se mencionó anteriormente, Burgos propone el relato periodístico como el género fundacional del Ecuador, algo que no sorprende en absoluto y cuyas semillas se pueden rastrear ya en la obra de Eugenio 
la complejidad de los sujetos actantes que habrían de conformarla se gestaba también a partir de una serie de documentos menos canónicos, y a pesar de que ni Sommer ni Burgos los mencionan, entre ellos también constaban las aventuras piráticas, dadas a la especificidad de la violencia, al menos en teoría, para la constitución del estado-nación:

\begin{abstract}
Durante el momento en el cual las identidades nacionales se delineaban y los proyectos nacionales emergían en Hispanoamérica, la piratería dejó de verse, exclusivamente, como un hecho innoble llevado a cabo por extranjeros; también se convirtió en una forma de heroísmo. Este cambio en la representación ficcional del pirata refleja la ausencia de un discurso hegemónico capaz de definir la identidad de la nación y de controlar los imaginarios oficiales que ayudaban a asegurar una conciencia nacional colectiva. (Gerassi-Navarro 72)
\end{abstract}

El pirata del Guayas posee componentes previsibles de cara a la ficción fundacional melodramática: un muchacho de baja condición, Bruno, se enamora de una chica llamada Ángela pero su matrimonio es imposible porque, nos enteramos al final del texto, esta resulta ser su media hermana. ${ }^{5}$ Bruno, sin saber el parentesco que los une, roba y mata para obtener dinero y así poder escapar con ella, que está esperando un hijo suyo. Se lo captura, se lo azota, se lo humilla públicamente y se lo deporta a las Galápagos -que funcionaban como cárcel en la época-, de donde escapa al mando de su empresa pirática en busca de venganza. Después de capturarlo, se lo condena a muerte no sin antes contarle que su madre cometió adulterio y que producto de ello su amada viene a ser su media hermana; al final se alegra de ir a la horca.

Como se pude intuir, la novela tampoco se encuentra libre de una lectura alegórica en la cual se evidencia lo romántico como una mediación política de la el cual no puede obtenerse cohesión alguna:

Es la retórica del erotismo la que organiza novelas patrióticas [...] Los típicos ejemplos en Latinoamérica son casi siempre historias de amantes a la deriva que representan regiones específicas, razas, partidos, intereses económicos, etc. Su pasión por la unión sexual y conyugal se desborda hacia una lectura sentimental con el afán de atraer a más partidarios con la razón y con el corazón. (Sommer 2-5)

Tal vez no sea de mayor importancia la anticipación de un texto a otro en cuanto a su publicación con respecto a la "ficción fundacional" nacional, así como tampoco

Espejo desde el siglo XVIII, conocido, tal vez falazmente, como el "precursor de la independencia". No obstante, El pirata del Guayas contradice su postura pues no fue escrita por entregas sino publicada como novela y, al contrario de la tan ansiada cohesión, postula un caos insufrible en el país recién fundado.

5 Caso similar al de la novela Cumandá o un drama entre salvajes, en donde los dos protagonistas, Carlos y Cumandá, resultan ser medios hermanos.

$111 \frac{\text { Revista Iberoamericana, Vol. LXXXV, Núm. 268, Julio-Septiembre 2019, } 923-940}{\text { ISSN 2154-4794 (Electrónico) }}$ 
aporta mayormente una discusión tocante a su género, pero sí resulta enriquecedor examinar el paralelismo contextual e histórico vis à vis el de la ficción que intenta representarlos, y sus consecuencias para el establecimiento del imaginario y la polisemia de las Galápagos, el Ecuador y América Latina. El "pirata literario" que mencionara Adorno con relación a la ficción como rechazo a la burguesía (224-26), ${ }^{6}$ se asemeja a la función del pirata ecuatoriano en la novela de Bilbao, que utiliza un espacio crucial para la modernidad occidental de modo divergente e incómodo con el fin de combatir indirectamente la tan anhelada ilusión decimonónica de cosmopolitismo latinoamericano.

La obra confirma el modo como el archipiélago ecuatoriano es un territorio cómodo y fértil, literariamente hablando, en cuanto a la postulación de distintas ideologías por medio de su representación. Pero una de sus valías principales reside en la preocupación por retratar la constitución caótica de las repúblicas recientemente independizadas, preocupación radicalmente diferente de aquellos textos que se escribieron en inglés sobre las islas y que distaban tanto de las inquietudes regionales. Si bien Bilbao toma prestado mucho de la historiografía, tanto o más incluso que el propio Herman Melville, ${ }^{7}$ resulta crucial observar cómo rebate las narrativas contemporáneas escritas en otros idiomas.

"Los hechos que han originado este trabajo [escribe al inicio de la novela] son tomados del proceso criminal que existe en la escribanía de Guayaquil. El que dudase puede ocurrir a ese archivo. Los nombres de los bandidos son otros de los que aquí se ponen" (18). Este apartamiento explícito de la escritura de ficción para postular la crónica "verdadera" suscita una interpretación histórico-política contra corriente de lo que Brennan llamaría los "mitos de la nación” (44). La explicitud de Bilbao al comienzo de su novela condiciona la recepción del texto para deconstruir la moral de valores decimonónicas normalmente utilizadas para afianzar el orden social nacional, dando a entender que el caos de la nación no se captura mejor por la narrativa ficticia. Que Bilbao se permita citar sus fuentes, tanto históricas como legales, en una manifiesta estrategia de autenticidad, también revela una ansiada preocupación por el capital simbólico del criminal en cuanto a su capacidad para cuestionar una serie de suposiciones falaces de jerarquía social, política y filosófica utilizando las oposiciones binarias. El origen disperso de este autor también es útil para cuestionar la tesis de Sommer, ¿qué ocurre cuando un extranjero escribe la denominada novela fundacional de una nación que no es la suya?, ¿cuál es el resultado de utilizar en la narración uno de los espacios de mayor notabilidad para la modernidad occidental en el siglo XIX?, ¿cómo interpretar

6 Si bien Adorno se refiere a la novela Rastros (1930) de Ernst Bloch (1885-1977) creo que la cita es pertinente.

7 Me refiero al libro de relatos de Melville The Encantadas, or Enchanted Isles publicado en 1856 como libro aunque desde 1854 se publicara como cuentos esporádicos en Putnam's Monthly Magazine.

$111 \frac{\text { Revista Iberoamericana, Vol. LXXXV, Núm. 268, Julio-Septiembre 2019, } 923-940}{\text { ISSN 0034-9631 (Impreso) }}$ 
la predisposición del bandido o del pirata para marginalizar el discurso constitutivo nacional?

El pirata del Guayas captura la dicotómica -y por demás reduccionista- división entre el modelo de la civilización y la barbarie, así como aquel de los bandos liberales y conservadores. Su importancia reside, sin embargo, en la capacidad de explicar una diferenciación de identidad de los habitantes de las Galápagos y los ecuatorianos continentales con respecto a la división entre una conducta trastornada, como la del personaje principal, y otra razonada, como las autoridades a las que somete. El trastorno del personaje principal se relaciona directamente con la reclusión penal y cómo dicha reclusión y aislamiento permiten definir la lógica de la irracionalidad, del mismo modo, como tal vez, se pueda intentar definir una lógica similar para la identidad ecuatoriana. Foucault sugiere que "el encarcelamiento de los locos por medio de las instituciones de nuestra propia elaboración nos permite discernir entre la verdad y la locura, lo marginal y no normal" (26). Si la identidad de la nación se está constituyendo a partir de las narraciones fundacionales, una hipótesis válida también deja entrever la circunscripción de sus límites dados a partir de los entes encarcelados. ¿Qué ocurre cuando la colectividad identitaria proviene de seres privados de libertad por la ley?

La trama central de la novela se enfrenta a la marginalidad que sugiere Foucault reproduciendo crónicas de prensa y anales históricos sobre un preso real apellidado Briones que, en 1852, se sublevó y escapó de las Galápagos con una cuadrilla de menos de diez hombres. Los prófugos secuestraron una embarcación estadounidense y se dirigieron hacia el continente. En el transcurso del viaje tomaron una nave dirigida a derrocar al gobierno de turno, la abordaron y acto seguido mataron a su tripulación en altamar. Al llegar a Guayaquil, Briones y sus secuaces se ufanaron de sus hazañas, pues alegaban haber peleado por la patria y derrotado al invasor. Si bien los piratas esperaban una recepción heroica fueron capturados y sentenciados a muerte cuando arribaron al territorio ecuatoriano (Luna Tobar 80-1 y Larrea 137-8).

Las figuras del reo y del pirata sirven para cotejarlas con las del país antes y después de su independencia; paralelismo importante que refleja una lucha idealista que, según Bilbao, es difícil de ganar por la fuerza pero sí es accesible por la razón. No queda claro, sin embargo, a qué razón se refiere, ¿tal vez a una en la cual gobierna la lógica de lo irracional como sugiere el teórico francés?, o ¿a una en la cual el supuesto preso-loco razona de mejor modo que la institución que lo recluye? La figura del pirata se capitaliza y toma mayor fuerza dialéctica porque, históricamente, no era la primera vez que Guayaquil se veía amenazada por corsarios, extranjeros o nacionales, cuyos saqueos en el siglo XVII, aún bajo la protección del virreinato, mantenían una presencia espectral y ominosa en el principal puerto del país.

La representación de las islas Galápagos entonces se ve matizada por una verosimilitud impostada en cuanto a la historiografía, por una división entre el margen y la norma así como por un hálito romántico no difícil de imaginar tanto por el contexto

$111 \frac{\text { Revista Iberoamericana, Vol. LXXXV, Núm. 268, Julio-Septiembre 2019, } 923-940}{\text { ISSN 2154-4794 (Electrónico) }}$ 
como por la agenda del escritor. De modo similar, la región insular aparece mediada por la convulsión del Ecuador decimonónico y por el modo como se lo presenta lo más alejado posible de la modernidad:

En este sitio árido y melancólico, apartado de toda comunicación con el resto del mundo; donde las lluvias caen con la fuerza del granizo, los vientos soplan con la violencia del huracán; donde de día el calor despliega su fuerza abrumadora y de noche el aire esparce un frío penetrante, donde el alimento es escaso, dificultoso y miserable y donde no se oye otro ruido que el estallido de las olas y el bramar de los huracanes; en este desierto poblado de insectos y de miseria se encontraba el lugar que las autoridades habían destinado para la purificación de los criminales del Ecuador. (20, énfasis añadido)

A la imagen del pirata la antecede aquella del recluso atormentado, alegóricamente la república latinoamericana antes de su emancipación. Si el reo sirve para construir un discurso en el que prima el encierro bajo una férula legislativa de coerción y explotación, metáfora del mal llamado yugo peninsular, el pirata encarna su opuesto antitético libertario, inherente a tal figura no solo en cuanto a la desobediencia de leyes sino también a la forma como muestra la ausencia de fronteras que pretenden contenerlo. Este ímpetu retoma con cierta fidelidad el entusiasmo por la empresa de autonomía que se había fraguado a inicios del siglo XIX, al margen de las leyes monárquicas reinantes para imponer las propias a posteriori, aunque estas fueran más idealistas que verdaderamente aplicables. Precisamente una de las tesis que Bilbao intenta defender propende a resaltar la razón bien argumentada en detrimento de la belicosidad recalcando, constantemente, sus beneficios, aunque se torna evidente observar que sin las armas parece ser imposible transformar el status quo:

La libertad del pirata para escoger su modo de vida se hizo posible solo a través de la violencia. Los escritores que discutían los proyectos nacionales futuros pudieron sentirse identificados con la piratería básicamente porque los hispanoamericanos solo fueron capaces de construir sus naciones independientes a través de la violencia. (Gerassi-Navarro 7)

Por otro lado, Lazo plantea, acertadamente y de modo similar a como Ahab, por ejemplo, utiliza el poder de la oratoria en el Pequod, que Bruno convence a sus compañeros con el uso apropiado de la retórica más que con el de la fuerza (231). ${ }^{8} \mathrm{La}$ libertad absoluta, justificada por medio de la fuerza, y que al final del relato fracasa

Así lo interpreta Lawson también, véase obras citadas. Las Encantadas, or Enchanted Isles de Melville dialoga y comparte el mismo espacio narrativo con la novela de Bilbao, de ahí que la comparación tenga validez.

$111 \frac{\text { Revista Iberoamericana, Vol. LXXXV, Núm. 268, Julio-Septiembre 2019, } 923-940}{\text { ISSN 0034-9631 (Impreso) }}$ 
rotundamente, se contrapone a aquella que intenta emular el pensamiento de una sociedad liberal "avanzada" y progresista, que favorece el narrador: "La supremacía de la espada sobre la inteligencia ha sido uno de esos resultados que tantas revoluciones ha costado a la América y una de las principales fuentes del despotismo que ha obstruido el desarrollo de las industrias y de las reformas" (83).

Surge entonces una contradicción en cuanto a la percepción histórica y real del lugar vis à vis los intereses de la sociedad recién constituida representada por los colonos continentales. Cuando el Ecuador tomó posesión de las Galápagos una de las bases argumentativas de la expedición comandada por José Villamil,, era establecer “el orden civil". No deja de llamar la atención que mientras se proponía esto se empezó por ocupar a las islas con reos: "Ninguno de los colonos iba como confinado, sino como colonizador voluntario, pero entre las recomendaciones que llevaba la comisión estaba la de buscar un lugar para un 'presidio' que el Gobierno se proponía mantener en aquellas islas" (Latorre 74).

Relata Villamil, una vez asentado en las islas, que vivía con "soldados de cuerpos insurreccionados de la República [...] y otros tal vez de peor condición” (Luna Tobar 265). Este prócer reclamó, con éxito, que se le otorgaran los títulos de propiedad de algunos terrenos de las Galápagos, lo cual obligó a que se redactaran informes situacionales de la empresa colonizadora desde que hubiera de iniciarse su toma de posesión. Un informe, escrito por el general Hernández, puntualiza:

Los pobladores [...] desmontaron y sembraron más de dos cuadras de tierra que a mi salida ofrecía a la vista las primeras muestras de producción: [...] la Floreana es una bellísima isla que puede tener como setenta millas en contorno y cuyo suelo particularmente desde una milla de las orillas del mar para el interior en su extremo feraz: allí hemos encontrado diversas plantas de los climas templados, cuyos frutos estaban a su mayor perfección: la papa entre otras es tan buena como la que se produce en los departamentos del interior. [...] la abundancia de agua, un excelente temperamento, la abundancia de peces, la inmensa cantidad de tortugas de mar y tierra que se encuentra a cada paso [...] es muy frecuentada por los buques empleados en la pesca de la ballena, [...] el año pasado más de setenta buques llegaron a su puesto [...] si la isla produjese los víveres que necesitan todos los buques vendrían allá en lugar de ir a otros puertos. [...] En el lugar a donde se va a fundar la población que ha sido nombrada por los pobladores Asilo de Paz se levantó un altar debajo de un techo rústico y por la primera vez fue celebrado el servicio divino. (citado en Borja 266, énfasis mío)

Es importante resaltar la diferencia entre lo que narra Bilbao y lo que escribe Hernández con respecto a las islas. Hay que recordar cómo el primero describe un

9 Criollo perteneciente a la élite del país, nacido en Nueva Orleans (1788-1865).

$111 \frac{\text { Revista Iberoamericana, Vol. LXXXV, Núm. 268, Julio-Septiembre 2019, } 923-940}{\text { ISSN 2154-4794 (Electrónico) }}$ 
"sitio árido y melancólico", donde los vientos soplan "con la violencia del huracán", el alimento es "escaso, dificultoso y miserable", y el paisaje es "un desierto poblado de insectos y de miseria". La imagen de las islas que las autoridades estatales y la empresa colonizadora privada intentan promulgar defiende una valía agrícola y comercial progresista; es decir un conato de la tan anhelada modernidad, totalmente irreal no solo en las islas sino también en el país. La verdad es que las dificultades de asentamiento en las Galápagos eran enormes dada la carencia de infraestructura y de mano de obra, el apartamiento geográfico y la falta de transporte marítimo, por demás infrecuente entre el continente y el archipiélago (Latorre 243). Es precisamente la mano de obra uno de los factores más trascendentales para las autoridades y la empresa villamiliana, pues ambas estaban convencidas de que la obtendrían sin costo, y a partir de ella nace la idea de la colonia penal. Dicho de otro modo, lo que la recién fundada república intentaba a través de Villamil era racionalizar la explotación y la dominación del reo utilizando el discurso del anhelo cosmopolita.

Al año de su llegada, Villamil escribió un informe, en 1833, en el cual explicaba su progreso y otras noticias relacionadas con el asentamiento galapaguense:

Los primeros pobladores están ya en estado de mantener continua ocupación [...] se han realizado mis esperanzas hasta hoy y tal es el prospecto que preveen, que creo $s i$ el gobierno les permitiese su ingreso al Ecuador, muy pocos o ninguno aprovecharía de la gracia, la razón está muy a la vista, todos tienen plantaciones que después de cubrir sus necesidades les deja un sobrante mensual y en dinero sonante [...] Apenas podría creer que estas son las mismas personas que ahora un año saqué la mayor parte de las cárceles del Estado. (citado en Latorre, 1999, 416-19, énfasis mío)

Tal y como se lee en este informe al prefecto de Guayaquil, según Villamil, los presos estaban satisfechos e incluso felices por el incentivo económico, además de que estaban encaminados hacia una supuesta reforma. En oposición a este discurso oficial que se va apartando en líneas sucesivas de la resistencia casi total del archipiélago a conquistarse, El pirata va construyendo una narración menos dependiente y servil al poder, es decir más "verídica", y dicha narración recrea una atmósfera angustiosa y pesimista en las islas.

El informe de Hernández resalta, falazmente, la creación de abundante tráfico comercial -“es muy frecuentada por los buques"- cuando en realidad:

[...] el aislamiento del grupo insular alejado de las ordinarias vías marítimas del Pacífico, privado de medios de comunicación con las ciudades del Continente, mantenía a los pocos habitantes de las remotas islas fuera de la protección de las leyes y lejos de la acción defensiva de verdaderas autoridades. (Larrea 148)

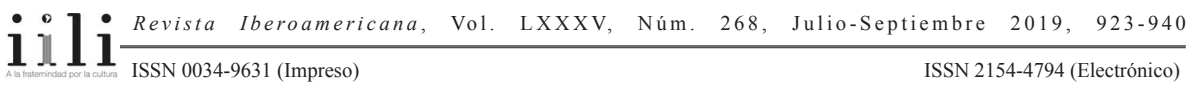


La ubicación privilegiada no tendrá importancia sino hasta el siglo XX dada por un azar geopolítico mundial concerniente al Canal de Panamá, una situación no inmanente a las islas o al Ecuador. Este es precisamente uno de los obstáculos para intentar llegar a una percepción del archipiélago ecuatoriano despojada de prejuicios, si bien esto resulta imposible: las islas se analizan como sitios estratégicos de cara a los intereses dominantes de turno más que como espacios en sí. Este fenómeno crea un significante de espacio abierto, vaciado, al cual se puede otorgar un significado a conveniencia.

Al desdeñar su jerarquía en relación a otras provincias, tratarlas como un referente anodino y no como un sitio propio por constituirse, el archipiélago se reconstruye localmente como un espacio anti-moderno, marginado de la doxa, lleno de antisociales, infértil. Paradójicamente, las Galápagos vienen a ser un espacio crucial, esencial para la empresa moderna después de las publicaciones darwinianas y la serie de preguntas de orden religioso, científico y filosófico que hubieran de desatar. Dicha esencia, postulada por el evolucionismo y sus consecuencias en la episteme de occidente, transforma al lugar en una especie de oikos inagotable, al que es imperativo volver y volver, pues es, al menos en teoría, el primer hogar, el origen total. ${ }^{10}$ Es decir un punto en el mundo que ejemplifica el salto teórico hacia una ontología razonada; en el ámbito local, sin embargo, su representación es tan opuesta que en vez de la razón priman crimen y caos.

Una de las causas de dicho fenómeno depende del modo como la isla destinada a ser presidio es un territorio a veces ilegible, manifestado en el topos de la inefabilidad, por ejemplo. Es también un espacio incómodo que funciona como un comodín interpretativo y cuya invención, al narrarse, se facilita. Permite evidenciar, al mismo tiempo, que la metrópoli es "civilizada" y "bárbara", esto ocurre porque de ella provienen los presos que habitan en el lugar; se intenta crear un lugar supuestamente auto contenido y alejado pero en él, al mismo tiempo, se encuentra la memoria traumática de la "monstruosidad" que viene del continente (Edmond 16). La narración de El pirata es una antípoda, en momentos casi total, de los informes oficiales sobre cómo se vive en las Galápagos, especialmente en lo referente a la identidad del país generada a través del grupo de presidiarios.

Los penados conformaban la mayoría de habitantes durante la época en cuestión y eran vistos por las autoridades como locos, como mano de obra gratuita y, cuando no trabajaban, como parte del paisaje. Si como plantea Edmond, "los lugares de encarcelamiento y destierro se convirtieron en una identificación de los cuerpos físicos que contenían" (énfasis añadida, 145), la identidad carcelaria vendría a ser el primer imaginario local de cara a la definición de las Galápagos en el Ecuador. No debería

10 Tal vez la cita más mencionada de Darwin al escribir sobre las Galápagos: "Hence, both in space and time, we seem to be brought somewhat near to that great fact-that mystery of mysteries-the first appearance of new beings on this earth" (378). 
entonces sorprender la tesitura central que defiende Ospina de cara a los habitantes del archipiélago en la actualidad: “[...] las islas están viviendo un intenso y veloz proceso de formación de un "sentimiento de diferencia" y de una "conciencia de comunidad". Ambos procesos son el principio de una identidad arraigada" (10).

El fluir de presidiarios pretende cortar sus nexos (anti)sociales con el continente, impostando seguridad, pero a la vez creando un efecto contrario, un movimiento de resistencia a aquel que procurara definirlas como un satélite aislado políticamente del Ecuador: los presos vinculan de una u otra forma al archipiélago con el país por su procedencia mientras que, al mismo tiempo, los textos extranjeros lo dividen. El informe de Hernández no menciona a la comunidad de reos y Villamil se refiere a estos contradictoriamente y con cierto recelo pues vive allí casi "sin apoyo ni defensa", mientras que a la vez "apenas puede creer que son las mismas personas que sacó de las cárceles". Este criollo latifundista recrea el imaginario de las islas a través de lo que Gillis denomina Seagirt: una idea fija en la cual el territorio insular se define por lo que lo rodea y no por lo que puede brindar de sí (19-31). No asombra entonces que para Villamil, así como para los funcionarios oficiales, el progreso, concebido del mismo modo como se lo concibe en el entorno continental (agricultura y ganadería fecundas, comercio tradicional próspero), fuera el criterio principal de evaluación del lugar.

Sobre este tema es de particular interés observar la oda que José Joaquín de Olmedo (1780-1847)-el poeta nacional del Ecuador-compuso para Villamil a modo de agradecimiento por haber rebautizado una isla con su nombre. El autor de "La victoria de Junín” escribió: "Estas afortunadas islas que un alma empuja / Hace mucho tiempo donadas al naciente Ecuador / Verán pronto florecer en sus asombrosas laderas / El arroz y las piñas, y las espigas doradas" (88). ${ }^{11}$ La intervención de Olmedo -cercano amigo de Bolívar ${ }^{12}$ y primer vicepresidente del país- es importante porque apadrina la colonización insular desde el perfil intelectual de la naciente sociedad ecuatoriana, enfatizando, como siempre, los criterios ideales de desarrollo cultural, comercial y agrario. Es harto elocuente, por un lado, que el poema esté escrito en francés, buscando

11 El original en francés: “Ces îles fortunées qu'un esprit agissant / Naguères a données à l'Écuador [sic] naissant, / Verront fleurir bientôt, dans leurs flancs étonnés, / Le riz et l'ananas, et les épis dorés". No es poco común encontrar poemas en francés de Olmedo y sus pares; el resto del poema: "Alors, ô Villamil, quand la nuit étoilée / Surprendra les travaux chéris de la journée, / Le Florien satisfait mêlera dans ses chants / Ton nom, et sa Filis, tes bienfaits et ses champs: / Entouré de ses fils, et caressant son chien, / Il redira toujours que sur le sol florien / Tu appelas le premier, parmi ces déserts bois, / Hommes, plantes, troupeaux, arts, plaisirs, mœurs / [et lois, / Tous les biens de la paix... de Cérès tous les dons, / Qui révèlent aux mers le bonheur des nations" (88).

12 Tuvieron varias discrepancias importantes, una de ellas en torno al célebre "Canto a Bolívar". Para una reinterpretación del tema léase el artículo de Burgos "Olmedo y Bolívar en conflicto: Una relectura de 'La victoria de Junín: Canto a Bolívar'”' (2008).

$111 \frac{\text { Revista Iberoamericana, Vol. LXXXV, Núm. 268, Julio-Septiembre 2019, } 923-940}{\text { ISSN 0034-9631 (Impreso) }}$ 
el previsible cosmopolitismo, lo que Siskind llama con acierto "deseo de mundo". ${ }^{13}$ Por otro, y concomitantemente con la idea de imitación de la metrópolis y la esencia francesa de civilidad, en el doceavo verso de la oda, Olmedo alabó a: "Hombres, plantas, rebaños, artes, placeres, costumbres / y leyes" (88).

La versificación de Olmedo es casi más engañosa e ilusoria que aquella emanada desde el discurso oficial por como contrasta con la representación de Bilbao, especialmente si se recuerda que ninguno de los dos tuvo la oportunidad de visitar las Galápagos: "Sus costas están guarnecidas de rocas escarpadas donde azota con estrépito un mar enfurecido [...] nada ofrece de notable [...] La Floriana presenta una triste perspectiva. Un conjunto de volcanes apagados" (19). La oda de Olmedo también revela una consideración inusual para con el territorio por parte de una de las figuras independentistas más importantes e influyentes del Ecuador, si bien fue Villamil el que envió el poema al editor del periódico El Colombiano, en 1832, para su traducción del español al francés y su posterior difusión.

El interés de Olmedo es de doble faz: por un lado ejemplificar la vía del cosmopolitismo para el país emulando el incuestionable modelo francés tanto en su lengua como en su arte, ciencia e ideas; y por otro responder a una vanidad propia, instaurada por la práctica onomástica, una constante en las Galápagos desde su descubrimiento. ${ }^{14}$ En efecto, el tema bautismal que históricamente refleja el vaivén imperial y la debilidad de la nación ecuatoriana para defender la soberanía conceptual y cartográfica, se reaviva y pretende ser central al proyecto de creación del estado-nación del siglo XIX. Con este afán intenta, aunque fracasa, rehabilitar la extensión estatal y predominio de la república conformada hace pocas décadas, utilizando las islas como modelo. Fracasa porque los nuevos nombres que Villamil utilizó nunca se pudieron establecer, si bien facilitaron la instauración, en 1892, de aquellos provenientes del viaje de Colón. ${ }^{15}$

Es preciso observar que al revisar el informe de Hernández y la cuestión de la mano de obra presidiaria, no debe llamar la atención que se esperaba que los presos trabajaran "gratis" para los latifundistas, pues durante el siglo XIX pocos terratenientes controlaban el gobierno y dominaban la vida social dedicada a mantener las desigualdades de raza y clase, y la esclavitud y el tributo (Rodríguez-Arenas X). Adicionalmente,

13 Es una de las tesis principales de Cosmopolitan Desires: Global Modernity and World Literature in Latin America (2014) con respecto a la literatura mundial y los modernistas latinoamericanos.

14 Los primeros nombres de las Galápagos fueron ciertamente hispanos, acuñados por Diego de Rivadeneira en 1546, pero luego las islas fueron informalmente rebautizadas por los británicos en el siglo XVII para más tarde cambiar, una vez más, a una denominación francesa, no oficial, en 1772 por Guillaume Derisle (Castillo 10). Hoy en día se utilizan tanto los nombres en inglés como en español; para información detallada sobre los nombres de cada isla véase Latorre (1999, 58-62).

15 Según Latorre la colonización de Villamil por "su ilusión de ser dueño del archipiélago" cambió los siguientes nombres: de Chatham a "Mercedes"; de Indefatigable a "Bolivia"; de Duncan a "Ana"; y de James a "Olmedo" (77).

$111 \frac{\text { Revista Iberoamericana, Vol. LXXXV, Núm. 268, Julio-Septiembre 2019, } 923-940}{\text { ISSN 2154-4794 (Electrónico) }}$ 
con relación a la posesión de las islas, Latorre menciona que la colonia había quedado instaurada según el modelo de hacienda habitual (78).

La figura del preso-pirata es entonces desagradable y contraproducente tanto para el discurso oficial como para ciertas narraciones extranjeras, a menos que los emisores del discurso hegemónico se pudieran servir de ella. Pero esta figura no es incómoda para la incipiente crónica latinoamericana que iba constituyéndose casi a la par de las naciones. ${ }^{16}$ Esto ocurre no solo por la fascinación romántica que existe por las narraciones de aventuras, de entre las cuales tanto el pirata como el reo sobresalen y desencadenan en fecundidad narrativa dadas las ventas y el interés romántico y morboso por el exotismo, sino también porque permite emular de mejor manera las pugnas de la época post independencia.

La metamorfosis trascendental, la del reo oprimido en el pirata libertario, arrastra entonces un movimiento importante que va alterando no solo la estasis que causara el aislamiento geográfico de las islas y del Ecuador, con respecto a Latinoamérica y a occidente, sino también aquel de orden político. Dicho movimiento, en la novela, proporciona varias claves para una relectura sobre la consecución de la independencia y la formación estatal y republicana. Cuando el narrador se refiere a los presos, señala que se creían libres y que querían formar un gobierno independiente, sin necesidad de obediencia alguna (Bilbao 49). Esta tendencia, en la novela de Bilbao uno de los criterios principales en cuanto a la definición de la nación ecuatoriana de cara al antes o al después del primer grito independentista de 1809, contradice frontalmente el estancamiento que se definiría en las narrativas de náufragos y en aquellas que enfatizan el paisaje, la fauna y la flora. Con respecto a estas últimas el ejemplo epítome sería The Voyage of the Beagle (1839) de Charles Darwin, y con respecto a las primeras el cuento de Melville titulado "Orbelus", basado en el texto de David Porter que relata las aventuras del náufrago irlandés Selkirk y que fue publicado en 1823. Como se sabe, los relatos de náufragos no están despojados de la episteme neoimperial y los intereses que acarrean consigo. Los reos refutan la percepción impuesta de isla desierta que los textos en inglés pretendían reafirmar:

decir que una isla está deshabitada es, siempre, una empresa cultural. Menciona solo las formas de vida que se relacionan con el poseedor del discurso dominante; borra toda otra clase de vida [...] Los biogeógrafos, en los últimos años, han puesto en tela de duda la suposición de que algunas islas están habitadas o deshabitadas, como si se tratara de un decreto aborigen. (Beer 40-1, énfasis mío)

16 Escribe Sommer: "Solo se obtiene la exhortación, además del deseo contagioso por un amor socialmente productivo y por un Estado donde el amor es posible, porque estos asuntos erótico-políticos pueden llegar a ser muy frustrantes" (6).

$111 \frac{\text { Revista Iberoamericana, Vol. LXXXV, Núm. 268, Julio-Septiembre 2019, } 923-940}{\text { ISSN 0034-9631 (Impreso) }}$ 
Resulta falsa la noción decimonónica de isla desierta que se fijaba con cierta insistencia en el imaginario galapaguense de entonces, desde Tomás de Berlanga (14901551), quien escribiera el primer texto que da cuenta de la existencia de las Galápagos en 1535. Pero el concepto de la isla desierta vuelve a aparecer con fuerza en el texto del historiador y explorador español Pedro Sarmiento de Gamboa (1532-1592) publicado en 1572, así como en aquellos escritos por bucaneros como William Dampier y William Cowley en los siglos diecisiete y dieciocho, hasta llegar a Darwin y a Melville. Bilbao, por otro lado, escoge incorporar a la figura del filibustero no solo porque le permite insertar el discurso de la potestad nacional sino también porque, convenientemente, el barco del que los presos logran apoderarse para escapar es de origen estadounidense. Si se llegara a escribir un ensayo borgeano titulado "Martí y sus precursores", o tal vez "Rodó y sus precursores", sin duda en él se podría nombrar a Bilbao, intuyendo antes que ellos el origen de una potencial neocolonización norteamericana.

Hablando de entes precursores, el "aborigen" que plantea Beer no aplica a las Galápagos dada la carencia de indígenas o de cualquier otro grupo que fuera originario del archipiélago, pero sirve para trazar un paralelo en el cual los presidiarios pasan a ser invisibles para el discurso dominante, sea este ecuatoriano o no, escrito en inglés o en español. Dicho de otro modo: la subjetividad presencial del Otro, reafirmada a través del tópico del pirata y del preso, pasa a ser medular para poder cotejarla con las narraciones constitutivas de identidad como un génesis que se encuentra viciado a priori. Dado que el náufrago siempre se define con respecto al interés del poder discursivo que lo expone, su propia configuración se ve cuestionada a pesar de tener un potencial origen identitario. Mientras algunos textos canónicos se centran en narrar cómo el náufrago conquista el paisaje, la flora, la fauna y transforma al lugar en un espacio habitable moldeado a su ontología ${ }^{17}$-trabajo, perseverancia, orden, valentía-, este texto se centra en narrar el punto de fuga, el pliegue, la violencia y la rebeldía del individuo, equiparándolo con el náufrago primero, por su modo de vida estático, y convirtiéndolo en pirata, después, para representar una libertad ilusoria y efímera. Si la figura del náufrago presenta una buena oportunidad para que los escritores extranjeros postulen sus intereses, aquella que recrea Bilbao con el reo-pirata, se da para contrarrestarla y a la vez manifestar los suyos.

Esta transformación entre uno y otro estadio de los personajes históricos bien puede explicarse por la referencia a Foucault citada con anterioridad: el océano opera como un espacio liminar donde se suscita la transformación, en la novela, de náufragos en piratas, desprovistos de raciocinio epigonal de la norma pero nunca carentes de la lógica constitutiva, apoyada en una violencia ineludible para obtener sus metas. La barbarie también tal vez se defina, complementariamente, por una carencia de lógica

${ }_{17}$ Robinson Crusoe sería el pre-texto más popular y al que hago alusión aquí.

$111 \frac{\text { Revista Iberoamericana, Vol. LXXXV, Núm. 268, Julio-Septiembre 2019, } 923-940}{\text { ISSN 2154-4794 (Electrónico) }}$ 
que se ejemplifica en la insensatez no solo de los actos criminales, sino también del aislamiento forzado y la pena de muerte que se impusieran desde la fundación nacional porque el modelo importado no necesariamente calza con la especificidad regional.

No obstante, sería un error pensar que "los piratas pueden competir por el control de las autoridades gubernamentales" (Lazo 230-1, énfasis mío) porque los golpes de estado venían desde dentro y se fraguaban con alianzas estratégicas mucho más poderosas y efectivas que las románticas que fingidamente los filibusteros emprendieron. La empresa de Flores que inspirara el relato de Bilbao, por ejemplo, evidencia más los coletazos de ahogado de este exmandatario que un verdadero peligro, pues cualquier intento de usurpar el poder tendría que tomarlo también en Quito y no solo en Guayaquil. La figura es imaginaria pero no carente de un alto capital simbólico: "El pirata -con sus imágenes provocativas de terror y de libertad- vino a corporizar las dificultades que muchas naciones experimentaron en su búsqueda de la formación nacional" (Gerassi-Navarro 4).

Este es otro de los motivos por los cuales Bilbao intenta dar mayor verosimilitud a su relato, para volver a agregar imaginariamente la tensión política de verdadero peligro, especialmente por el condicionamiento histórico de Guayaquil con respecto a los filibusteros. La obra tuvo bastante acogida al momento de su publicación, cosa que explica su reedición a inicios del siglo XX:

En la [segunda] edición de El pirata del Guayas publicada por El Telégrafo de Guayaquil en 1904, los editores [...] muestran gran sorpresa ante el hallazgo de esta obra de Bilbao: “...En la primera parte reproduciremos la obrita titulada "El pirata del Guayas" [...] es rarísima y casi podemos asegurar que el ejemplar que poseemos es el único que existe en Guayaquil; pues la edición [original] fue destruida y el referido ejemplar ha sido uno de los pocos que se salvaron y procede del archivo de Rocafuerte. En la época en que se dio a la luz hizo una gran sensación, y nuestros ancianos le recuerdan con gran interés; pero las nuevas generaciones no le conocen y creemos que prestarán toda atención a esas páginas conmovedoras o terribles en las que palpita uno de los dramas más interesantes de la vida real” (IV). (Quiroz 10)

La popularidad de El pirata muestra una de las formas de escritura popular de las Galápagos en el imaginario ecuatoriano, acaso la primera de ellas que se difundiera ante la nación entera, radicalmente distinta de la diseñada por los extranjeros. La narración de Bilbao nunca es ajena a la noción de autoridad gubernamental, así como tampoco se desentiende de la potestad del Ecuador sobre el archipiélago y sus escasos habitantes, y no está exenta de una reflexión crítica tocante al código penal con el que se fundara el país. En vista de que el autor es un intelectual polifacético, célebre en círculos sudamericanos selectos, y a razón de que proviene de una clase criolla con curiosidad política representativa de las "reputadas familias santiaguinas" (Quiroz 18), es lógico que en su novela se puedan rastrear temas inherentes al debate constitutivo

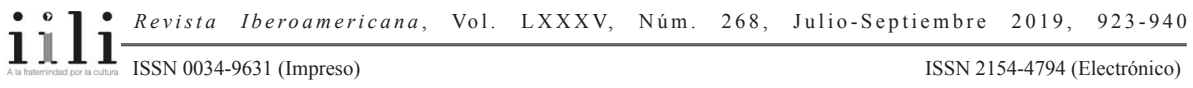


de Latinoamérica. Este fenómeno es saludable y provechoso cuando inicia una senda relativamente novedosa de significación de las Galápagos, con matices locales y próximos a la realidad social en cuanto al modo de mirar las islas desde dentro versus aquel que se instituiría desde fuera.

Por otro lado, es importante recalcar que al separar de modo simplista los bandos políticos, así como las posturas denominadas civilizadas de aquellas mal llamadas bárbaras, su discurso regenera el paternalismo reinante del siglo XIX de las primeras en contraste con las segundas. Paradójicamente lo que no logran del todo, ni de modo tan explícito, Melville o Darwin ${ }^{18}$-recrear al Otro como salvaje- Bilbao consigue con facilidad. Por dar un ejemplo, el uso de la endogamia, tema bastante frecuente entre los indígenas o entre las poblaciones aisladas mal designadas "salvajes", y que a momentos resurge en las narraciones de occidente como uno de los componentes de la barbarie junto con, por dar otro ejemplo, el canibalismo.

La ruptura familiar también es significativa porque la consolidación de un núcleo doméstico en el entorno melodramático es uno de los principales factores que se repite en la "narración fundacional". Esta barbarie, según el autor chileno, sería una condición aprendida e instaurada por un mal manejo social, legal y estatal de las autoridades, y no provendría de una práctica consuetudinaria cultural de tal o cual grupo antropológico inherente a ella. Bilbao sugiere que el bárbaro existe como producto del sistema, especialmente el desarrollado en torno a la función judicial y legislativa coloniales. Los editores que reimprimieron su obra son, además, conscientes del comienzo de la revolución liberal ecuatoriana que inició con la presidencia de Eloy Alfaro (1895), seguida por el gobierno de Leonidas Plaza quien, a pesar de ser más conservador que su antecesor, desde 1901 "llevó a cabo las reformas liberales más radicales" (Ayala Mora 35). El Telégrafo, el periódico que reeditó la novela, fue un diario influyente que pretendía entonces suscitar un cambio legal a sabiendas de la constitución propincua a la ideología liberal que habría de redactarse en 1906, la denominada Carta Magna, en el segundo mandato de Alfaro que duró hasta 1911.

Es decir, este texto calza perfectamente para apadrinar una constitución liberal y es satisfactorio para los supuestos modernizadores del estado incluso cincuenta años después de su publicación inicial. Las rediciones responden entonces no solo al exotismo, sino también a la ambición política que buscaba la aprobación de la famosa Carta. La imagen del salvaje reo y del libertario pirata reaviva a la isla-presidio galapaguense como un lugar sentimental similar a como narraciones anteriores a ella iniciaran el mito. Estas relatan principalmente cómo bucaneros y filibusteros, ingleses o estadounidenses en su mayoría, desde su descubrimiento en el siglo XVI, usaban el archipiélago como

18 No lo logran del todo porque sus textos no circulan por Latinoamérica y porque desdeñan el ámbito político.

$111 \frac{\text { Revista Iberoamericana, Vol. LXXXV, Núm. 268, Julio-Septiembre 2019, } 923-940}{\text { ISSN 2154-4794 (Electrónico) }}$ 
guarida beneficiosa por los alimentos, la ubicación y también por la carencia de control del país y su falta de habitantes (Charvet 253-303). Este hecho condiciona el futuro de la región y al modo cómo, después de la ola de visitantes, conferencias, estudios de biología, filosofía y teología que causara Darwin en la comunidad internacional, se la definiera. En el extranjero es o bien un destino turístico o bien un laboratorio que atrae, a priori, por la curiosidad que despiertan su flora y su fauna; pero en el Ecuador la atracción florece por otros motivos hasta mediados del siglo XX, dependientes por lo general de sucesos violentos atados a la especificidad de la constitución del estadonación latinoamericanos: "[...] la atracción casi obligatoria de la colonia penal como lugar turístico" (McMahon 196).

La violencia con la que principiara la representación galapaguense en el Ecuador desató un entusiasmo casi enfermo en la población que era muy dispar a la exaltación oficial que pretendía labrar fortunas comerciales buscando las simientes de la modernidad, por un lado, o usar las Galápagos como un comodín de canje o alquiler para asegurarse otros beneficios políticos mundiales, por otro. Una vez más se desplaza el modo de valorarlas, o menospreciarlas, según la agenda y la autoridad del escritor y del discurso dominante. Se debe recalcar que la bibliografía sobre el tema, generalmente, no cuestiona la isla como presidio sino el tipo de reos que debieron ocuparla, lo que permite entrever hasta qué punto la ansiedad por alcanzar un paradigma de sociabilidad influyó en su imaginario y como se articuló esta localidad destinada a la reclusión, siempre constituida desde el pensamiento latinoamericano ansioso de cosmopolitismo.

Este fenómeno llega a instaurarse con absoluta comodidad en la historia y la sociedad ecuatorianas, carente de un aparato crítico que lo cuestione. Las otras dos crónicas rojas que el periódico El Telégrafo publicó junto con El pirata en 1904 reafirman esta condición; crónicas que servirán como pilares para narrar las Galápagos en el siglo XX dentro del Ecuador. La mayoría de las obras ecuatorianas que representan al archipiélago incluyen, en mayor o menor medida, los crímenes y el terror de finales del siglo XIX. Es decir, un referente obligado dentro del país para establecer una imagen conveniente para el discurso oficial con el fin de presentar la idea de lo indomable-sea el reo, el pirata o el náufrago; sea la flora o la fauna-, y así justificar su negligencia administrativa. Este imaginario se leía tal vez en la época de modo más atractivo que la aburrida teoría de la selección natural que propusiera aquel célebre científico inglés.

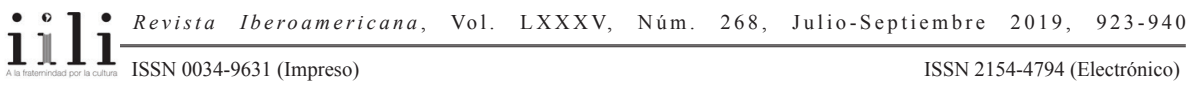




\section{OBRAS CITADAS}

Adorno, Theodor W. Notas sobre literatura. Antonio Brotons-Muñoz, trad. Rolf Tiedemann, ed. 11 Vol. Madrid: Ediciones Akal, 2003.

Ayala Mora, Enrique. Nueva historia del Ecuador. Quito: Corporación Editora Nacional Grijalbo, 1983-1995.

Beer, Gillian. "Island Bounds." Islands in History and Representation. Rod Edmond y Vanessa Smith, eds. Londres: Routledge, 2003. 32-42.

Berlanga, Fray Tomás de. "Carta a Su Magestad de Fray Tomás de Berlanga, describiendo su viaje desde Panamá á Puerto Viejo, e los trabajos que padeció en La Navegacion”. Colección de documentos inéditos relativos al descubrimiento, conquista y organización de las antiguas posesiones españolas de América y Oceanía. Tomo XLI, Cuaderno II. Madrid: Imprenta de Manuel G. Hernández, 1884. 538-544.

Bilbao, Manuel. "El Pirata del Guayas". Los crímenes de Galápagos (Archipiélago de Colón) El Pirata del Guayas. Asesinato de Valdizán; Asesinato de Cobos y Reina. Guayaquil: Impr. de El Telégrafo, 1904. 12-96.

Borja, Luis Felipe. "Documentos importantes acerca de Galápagos". Boletín de la Academia Nacional de Historia antes Sociedad Ecuatoriana de Estudios Históricos Americanos 26/68 (1946): 264-68.

Brennan, Timothy. "The National Longing Form." Nation and Narration. Homi K. Bhabha, ed. Nueva York: Routledge, 1990. 44-70.

Burgos, Carlos. "Olmedo y Bolívar en conflicto: una relectura de 'La Victoria de Junín: canto a Bolívar'." Semiosis: Seminario de Semiótica, Teoría, Análisis 4/8 (2008): 193-235.

Carrión, Benjamín. "Selección y Prólogo." Las Catilinarias. El Cosmopolita. El Regenerador. España: Biblioteca Ayacucho, 1985. IX-XXXVIII.

Charvet, Sylvia Paola. "Colonialismo y colonización de las Islas Galápagos: un doble proceso depredador". Cultura: Revista del Banco Central del Ecuador 8/24b (1986): 711-23.

Cowley, William. "A Short Account of My Voyage Round this Terestiall Globe of the World from Virginia to England and through the Great South Sea." Miscellanea Curiosa: Collected by Dawson Turner. IV Vol. Richmond: Virginia Historical Society, 1686.

Dampier, William. The Voyages and Adventures of Capt. William Dampier Wherein are Described the Inhabitants, Manners, Customs, ... \& c. of Asia, Africa, and America. Londres: printed in the year, 1776.

Darwin, Charles. The Origin of Species and the Voyage of the Beagle. Richard Dawkins, ed. Nueva York: Alfred A. Knopf, 2003.

Debord, Guy. La sociedad del espectáculo. José Luis Pardo, trad. España: Pre-Textos, 2010 . 
Edmond, Rod. "Abject Bodies/Abject Sites: Leper Islands in the High Imperial Era." Islands in History and Representation. Rod Edmond y Vanessa Smith, ed. Londres: Routledge, 2003. 133-145.

Foucault, Michel. Madness and Civilization: A History of Insanity in the Age of Reason. Londres: Tavistock Publications, 1971. Folie Et Déraison. English.

Gerassi-Navarro, Nina. Pirate Novels: Fictions of Nation Building in Spanish America. Durham: Duke UP, 1999.

Gillis, John R. "Taking History Offshore: Atlantic Islands in European Minds, 14001800." Islands in History and Representation. (2003).

Larrea, Carlos Manuel. El Archipiélago de Colón (Galápagos) Descubrimiento, exploraciones cientificas y bibliografia de las islas. 2.th ed. Quito: Editorial Casa de la Cultura Ecuatoriana, 1960.

Latorre, Octavio. El hombre en las islas encantadas: la historia humana de Galápagos. 1a ed. Quito: 1999.

Lawson, Andrew. "Moby-Dick and the American Empire." Comparative American Studies: An International Journal 10/1 (2012): 45-62.

Lazo, Rodrigo J. "Filibustering an Empire: Transamerican Writing and United States Expansionism.” Ph.D. University of Maryland College Park, 1998. United States, Maryland.

León Mera, Juan. Cumandá: O drama entre salvajes. Madrid: Espasa-Calpe, 1967.

Luna Tobar, Alfredo. Historia política internacional de la islas Galápagos. Quito: Ediciones Abya-Yala, 1997. Biblioteca del Pensamiento Internacionalista del Ecuador 2.

McMahon, Elizabeth. "The Gilded Cage. From Utopia to Monad in Australia's Island Imaginary." Islands in History and Representation. Rod Edmond y Vanessa Smith, eds. London: Routledge, 2003. 190-202.

Melville, Herman, and John Updike. The Complete Shorter Fiction. Londres: Everyman's Library; Distributed by Random House (UK) Ltd, 1997.

Mills, Nick. "Economía y sociedad en el periodo de la Independencia (1780-1845). Retrato De Un País Atomizado." Nueva historia del Ecuador. Enrique Ayala Mora, ed. 6 Vol. Quito: Corporación Editora Nacional Grijalbo, 1983-1995. 127-163.

Olmedo, D. José Joaquín, and Clemente Ballén. Poesías, edición corregida conforme á los manuscritos o primeras ediciones, con notas, documentos y apuntes biográficos por Clemente Ballén. Paris: Garnier hermanos, 1896.

Ospina, Pablo. Identidades en Galápagos: el sentimiento de una diferencia. 1.th ed. Quito: Ediciones Trama, 2001.

Porter, David. A Voyage in the South Seas, in the Years 1812, 1813, and 1814 with Particular Details of the Gallipagos and Washington Islands. Londres: Sir R. Phillips, 1823. Variation: American Culture Series; 388.5.

$111 \frac{\text { Revista Iberoamericana, Vol. LXXXV, Núm. 268, Julio-Septiembre 2019, } 923-940}{\text { ISSN 0034-9631 (Impreso) }}$ 
Quiroz, Mabel. Manuel Bilbao and the First Chilean Historical Novel: Critical Introduction and Annotated Edition of 'the Great Inquisitor', 2008.

Riofrío, Miguel, and Flor María Rodríguez-Arenas. La emancipada. 1.th ed. Buenos Aires: Stockcero, 2005.

Rodríguez-Arenas, Flor María. "La narración indígena en las Crónicas de Indias: un caso en la miscelánea antártica." Revista de Crítica Literaria Latinoamericana 14/28 (1988): 195-213.

Sarmiento de Gamboa, Pedro. Historia de los Incas. Madrid: Miraguano Ediciones: Ediciones Polifemo, 1988. Biblioteca de viajeros hispánicos 4.

Siskind, Mariano. Cosmopolitan Desires: Global Modernity and World Literature in Latin America, 2014.

Sommer, Doris. Foundational Fictions: The National Romances of Latin America. Berkeley: U of California P, 1991.

Palabras clave: Manuel Bilbao, ficción fundacional, las Galápagos, espacio antimoderno, preso-pirata

Recibido: $\quad 12$ julio 2015

Aprobado: $\quad 6$ julio 2016 